\title{
Sinus versus nonsinus tachycardia in the emergency department: Importance of age and heart rate
} Duane S Pinto, Kalon K Ho, Peter J Zimetbaum, Alexander Pedan and Ary L Goldberger* \author{
Massachusetts, USA \\ Email: Duane S Pinto - dpinto@caregroup.harvard.edu; Kalon K Ho - kho@hcri.harvard.edu; \\ Peter J Zimetbaum - pzimetba@caregroup.harvard.edu; Alexander Pedan - alex@clinepi.bwh.harvard.edu; \\ Ary L Goldberger* - agoldber@caregroup.harvard.edu \\ * Corresponding author
}

Address: From the Cardiovascular Division, Beth Israel Deaconess Medical Center, Boston, Massachusetts; Harvard Medical School, Boston,

Published: 05 August 2003

BMC Cardiovascular Disorders 2003, 3:7
Received: 24 April 2003

Accepted: 05 August 2003

This article is available from: http://www.biomedcentral.com/|47|-226I/3/7

(C) 2003 Pinto et al; licensee BioMed Central Ltd. This is an Open Access article: verbatim copying and redistribution of this article are permitted in all media for any purpose, provided this notice is preserved along with the article's original URL.

\begin{abstract}
Background: The emergency department diagnosis of sinus versus nonsinus tachycardia is an important clinical challenge. The objective of this study was to identify subjects with a high prevalence of nonsinus tachycardia.

Methods: Heart rate and cardiac rhythm were prospective reviewed in 500 consecutive patients with heart rate $\geq 100$ beats/min in a busy emergency department. A predictive model based on age and heart rate was then developed to identify the probability of nonsinus tachycardia.

Results: As age and heart rate increased, nonsinus tachycardias became more frequent. The probability of nonsinus tachycardia in a subject $\geq 7 \mid$ years with heart rate $\geq|4|$ beats/minute was $93 \%$, compared to only three percent in a subject $\leq 50$ years with heart rate $100-120$ beats/minute. A simple point score system based on age and heart rate helps predict the probability of sinus tachycardia versus nonsinus tachycardia.

Conclusion: Nonsinus tachycardia is significantly more common than sinus tachycardia in elderly patients in the emergency department. The diagnosis of sinus tachycardia becomes much less likely as age and heart rate increase.
\end{abstract}

\section{Background}

Tachycardia is a very common clinical finding in the emergency department (ED), and the differential diagnosis is often challenging. For example, at rapid heart rates, atrial activity may be obscured, and irregularity associated with atrial fibrillation (AF) may be difficult to appreciate. This prospective study evaluates a rapid means of identifying subjects at high risk for nonsinus tachycardia (NST) based on age and heart rate (HR).
First, we assessed the prevalence of NST in subjects presenting to the ED. Then we developed a simple system to help predict the probability of NST based on age and HR. Used as a tool in the evaluation of tachyarrhythmias in the acute setting, this system should help estimate the pre-test probability of a NST and, therefore, aid in the interpretation of the 12-lead electrocardiogram (ECG). 


\section{Methods}

We prospectively reviewed ECGs from 500 consecutive patients with $H R \geq 100$ beats/min (bpm) evaluated in the ED at Beth Israel Deaconess Medical Center over a 9 week period. Approximately 5 tracings with $H R \geq 100 \mathrm{bpm}$ were identified each day. This patient population included both surgical and medical subjects. Patients who presented in cardiac arrest or who required emergent electrical cardioversion were excluded. All ECGs were reviewed by a cardiologist and classified as either sinus tachycardia (ST) or NST. The NST group included AF, atrial flutter, paroxysmal supraventricular tachycardias (PSVTs) including atrial tachycardias and indeterminate nonsinus rhythms. No ventricular tachycardia was observed in the population. No subject was excluded. If multiple tracings were obtained, the single tracing with maximum HR was selected.

\section{Statistical Analysis}

To develop a simple screening system to estimate the likelihood of ST versus NST, we used the following procedure. Subjects were classified into three age categories: $\leq 50,51-$ 70 , and $\geq 71$ years. These groups were subclassified into three HR categories: 100-120, 121-140, and $\geq 141 \mathrm{bpm}$. To derive and then validate the statistical model, logistic regression models were developed from 349 randomly selected patients from the entire cohort of 500 patients. The models were then tested using a validation set of the remaining 151 patients. These models established HR and patient age as highly significant $(\mathrm{p}<0.0001)$ predictors of NST.

The predictive model was developed using variables representing each of the age and HR groups in multivariate regression analysis. Dividing the coefficients of the regression model to the by 0.5 and rounding to the nearest integer created a simplified point score index. Model fit and discrimination were evaluated [1]. Statistical analyses were performed using SAS for Windows version 6.12 (SAS Institute, Cary, NC). Frequencies were compared using $\chi^{2}$ or Fisher's exact tests, and a 2 -sided p-value $<0.05$ was required for statistical significance.

\section{Results}

The mean age of the population was 65 years (SD +/-19 years; range 14-103). Sinus tachycardia was the most common rhythm overall, present in $70 \%$ of subjects. Of the $30 \%$ of subjects with NST, AF was the most common arrhythmia and accounted for $69 \%$ of such cases. Five percent of subjects were in PSVT and two percent were in atrial flutter. No ventricular tachycardia was identified in this cohort.

For all age groups, as HR increased, NST became more frequent. For all HR categories, as age increased, NST also became more frequent. Only one percent of subjects with age $\leq 50$ years and HR 100-120 bpm were in NST, while $88 \%$ of subjects with age $\geq 71$ years and $H R \geq 141 \mathrm{bpm}$ were in NST $(\mathrm{p}<0.0001)$. Similarly, only $18 \%$ of patients with HR $100-120 \mathrm{bpm}$ were in NST, compared to $79 \%$ of patients with $\mathrm{HR} \geq 141 \mathrm{bpm}(\mathrm{p}<0.0001)$ (Table 1).

There were no significant differences in the prevalence of NST between the derivation and validation sets. The point score for each patient was computed by assigning 0 points for age $\leq 50$ years, 3 points for age 51-70 years, and 5 points for age $\geq 71$ years. Subjects were also given 0 points for HR 100-120 bpm, 3 points for HR 121-140 bpm, and 8 points for $H R \geq 141$. The sum of the points for age and $\mathrm{HR}$, ranging from 0 to 6.5 , placed the patient in one of seven risk factor categories.

The predicted probabilities of NST derived from the final multivariate logistic regression model are given in Table 1. Comparison of the predicted prevalences of NST from the regression model with the observed prevalences in the derivation and validation sets demonstrated a good fit (Hosmer-Lemeshow Goodness-of-Fit $\chi^{2}$ p-value of 0.92 and 0.82 for the derivation and validation sets, respectively). The discriminatory function, or the ability of the model to predict NST, was good with the area under the receiver operating characteristic curve of 0.8 for both the derivation and validation sets.

\section{Discussion}

The central finding of the study was the very high prevalence of NST in elderly subjects presenting to the ED with rapid HR. Analyses of arrhythmias in elderly patients admitted to the emergency or acute geriatric units have estimated the overall prevalence of supraventricular arrhythmias to be $20-30 \%[2,3]$. We found NST in $60-$ $90 \%$ of patients $\geq 71$ years with $\mathrm{HR}>120 \mathrm{bpm}$ in an acute setting.

The most common NST was AF, accounting for $69 \%$ of cases. AF was found in almost $20 \%$ of the entire study group, a much higher prevalence than reported in other non-acute populations $[4,5]$. The very high prevalence of $\mathrm{AF}$ in our ED population may identify a more severely ill patient subset with more concurrent medical problems. Of note, all-cause and cardiovascular mortalities in the elderly with $\mathrm{AF}$ are doubled compared to those without AF [6-8].

Our data show that the diagnosis of ST becomes less likely as HR increases. While ST is the most common arrhythmia in young patients, NSTs are more common in elderly patients. Based on our ED data, more than $80 \%$ of subjects $\geq 51$ years with $H R \geq 141 \mathrm{bpm}$ can be expected not to be in sinus rhythm. Conversely, a subject $\leq 50$ years with 
Table I: Prevalence and Predicted Probabilities* of Nonsinus Tachycardia (NST) Based on Age and Heart Rate (HR)

\begin{tabular}{|c|c|c|c|}
\hline \multirow[t]{2}{*}{ Age (years) } & \multicolumn{3}{|c|}{ Heart Rate (beats/min) } \\
\hline & $100-120$ (0 Points) & | $2|-| 40$ (3 Points) & $\geq|4|$ (8 Points) \\
\hline$<50$ (0 Points) & 0 Points & 3 Points & 8 Points \\
\hline Predicted Probability of NST & $3 \%$ & $13 \%$ & $62 \%$ \\
\hline Observed Probability of NST & $1 \%(1 / 77)$ & $13 \%(4 / 30)$ & $67 \%(6 / 9)$ \\
\hline 5 I-70 (3 Points) & 3 Points & 6 Points & I I Points \\
\hline Predicted Probability of NST & $13 \%$ & $39 \%$ & $86 \%$ \\
\hline Observed Probability of NST & $12 \%(14 / 114)$ & $40 \%(8 / 20))$ & $75 \%(15 / 20)$ \\
\hline >7I (5 Points) & 5 Points & 8 Points & 13 Points \\
\hline Predicted Probability of NST & $28 \%$ & $62 \%$ & $93 \%$ \\
\hline Observed Probability of NST & $30 \%(50 / 165)$ & $59 \%(20 / 4 I)$ & $88(21 / 24)$ \\
\hline
\end{tabular}

*Probability of NST is given by the equation: $\ln (\mathrm{p} / \mathrm{I}-\mathrm{p})=\left[-3.536+(1.099 \times\right.$ score $)-\left(0.0235 \times\right.$ score $\left.\left.^{2}\right)\right]$

HR $\leq 120$ bpm has a 99\% probability of having ST. These findings are consistent with the observation that the sinus node's ability to generate rapid rates decreases with increasing age, making rapid sinus rhythms quite unlikely at advanced ages. There is a decrease in maximal HR that occurs with physiological aging which may be due to a combination of factors, including intrinsic sinus node disease, ischemia, and alterations in afferent baroreceptor sensitivity and autonomic input and responsivity. The inability to augment heart rate appropriately in response to exercise or physiologic stress has been termed chronotropic incompetence and may be present in $40-70 \%$ of elderly subjects $[9,10]$. More importantly, nonsinus tachycardias become more frequent as patients age due to the increased prevalence of structural heart disease in the elderly population $[11,12]$. While older patients frequently come to the emergency department primarily with cardiovascular symptoms, younger patients often present to the ED for noncardiac reasons and may be expected, therefore, to have a higher prevalence of sinus tachycardia.

Finally, we note that this study did not address the role that specific disease processes made in precipitating or exacerbating NST. For this reason, the ability to generalize these findings to otherwise healthy, elderly patients in the outpatient setting is limited.

\section{Conclusions}

Based on our ED findings, physicians caring for subjects in the ED should have a very high suspicion for a primary NST, rather than a secondary ST, particularly in the elderly, tachycardic subject. Use of our a simple table (or score) incorporating age and heart rate may alter the pretest probability of NST for a given patient, aiding in the acute interpretation of the 12-lead ECG. Such assessments of elderly patients in the ED may also have implications for the rapid triage and definitive treatment of these patients.

\section{Author's Contributions}

DP performed the data collection, ECG analysis, and manuscript preparation.

$\mathrm{KH}$ and AP performed the statistical analysis and assisted in manuscript preparation.

PZ assisted in study design, ECG analysis and manuscript preparation

AG envisioned the project, assisted in study design, manuscript preparation and ECG analysis.

All authors have read and approved the final manuscript.

\section{Competing Interests}

None declared.

\section{Acknowledgements}

This work was supported by a grant from the G. Harold and Leila Y. Mathers Charitable Foundation, and the National Institutes of Health/National Center for Research Resources (P4I RRI3622) (Dr. Goldberger). The authors would like to thank Elio Fine for her invaluable technical assistance in carrying out this study.

\section{References}

I. Applied Logistic Regression. New York: John Wiley and Sons Inc 1989.

2. McComb JM: Tachycardias in the elderly. J $R$ Soc Med 1994, 87:794-7.

3. Patel KP: Electrocardiographic abnormalities in the sick elderly. Age Ageing 1977, 6:163-7.

4. Feinberg WM, Blackshear JL, Laupacis A, Kronmal R and Hart RG: Prevalence, age distribution, and gender of patients with atrial fibrillation. Analysis and implications. Arch Intern Med 1995, I 55:469-73. 
5. Wolf PA, Abbott RD and Kannel WB: Atrial fibrillation as an independent risk factor for stroke: the Framingham Study. Stroke 1991, 22:983-8.

6. Cameron A, Schwartz MJ, Kronmal RA and Kosinski AS: Prevalence and significance of atrial fibrillation in coronary artery disease (CASS Registry). Am J Cardiol 1988, 61:7|4-7.

7. Gajewski J and Singer RB: Mortality in an insured population with atrial fibrillation. Jama 198I, 245: 1540-4.

8. Kannel WB, Abbott RD, Savage DD and McNamara PM: Epidemiologic features of chronic atrial fibrillation: the Framingham study. N Engl J Med 1982, 306:1018-22.

9. Katritsis D and Camm AJ: Chronotropic incompetence: a proposal for definition and diagnosis. Br Heart J 1993, 70:400-2.

10. Camm AJ and Fei L: Chronotropic incompetence - Part II: Clinical implications. Clin Cardiol 1996, 19:503-8.

II. Astrand I: Aerobic work capacity in men and women with special reference to age. Acta Physiol Scand 1960, 49:1-92

12. Astrand I: The physical work capacity of workers 50-64 years old. Acta Physiol Scand 1958, 42:73-86.

\section{Pre-publication history}

The pre-publication history for this paper can be accessed here:

http://www.biomedcentral.com/1471-2261/3/7/prepub

Publish with Bio Med Central and every scientist can read your work free of charge

"BioMed Central will be the most significant development for disseminating the results of biomedical research in our lifetime. "

Sir Paul Nurse, Cancer Research UK

Your research papers will be:

- available free of charge to the entire biomedical community

- peer reviewed and published immediately upon acceptance

- cited in PubMed and archived on PubMed Central

- yours - you keep the copyright 